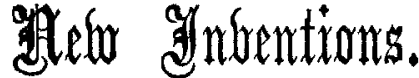

\section{NEW STRICTURE DILATOR.}

Messrs. Annold and Sons (of West Smithfield, London) have constructed for me an instrument which I hope will be appreciated by the profession. The troublesome and painful system of passing catheters and bougies for strictures ought certainly to be superseded by some procedure less irritating to the patient and more convenient to the practitioner. may be secured by altering the tension on both sides or on one only. The retractors are made of varying sizes and lengths, and with blunt or sharp hooks as desired, but for retracting the abdominal parietes the proximal end is fashioned like a flat pothook but without prongs. For tracheotomy and operations on the middle line of the neck, operations on blood-vessels of the limbs, abdominal sections, and in any situation where bilateral traction can be employed, these retractors will be found useful, especially where one is short-handed as regards assistants.

Some of the advantages possessed by these hooks are:Less handling of the wound is required; more room is obtained in which to work, and less assistance is neces-

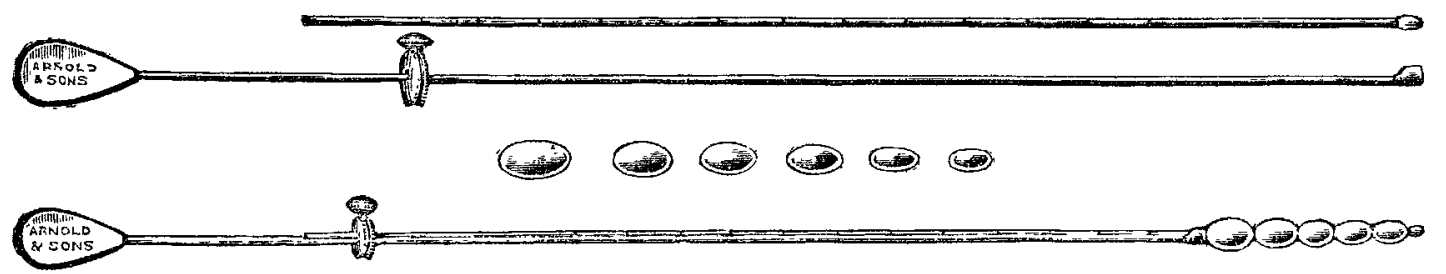

sary ; it is, therefore, more easy to maintain asepsis. I am indebted to Professor Jordan Lloyd, of Birmingham, for permission to modify his well-known retractors, and to Messrs. Down Bros., of St. Thomas's-street, London, S.E., for the care and patience they

The instrument illustrated here consists of a director, a have displayed in carrying out my wishes. propeller, and twelve beads. The director is a flexible metal stem terminating in a bulb, the stem being marked at every half inch. The propeller, which is used to push the beads along the director, has a terminal bulb (perforated), a handle, and a metal ring with hole to receive director and screw to clamp it. The beads are made of metal and represent the different catheter ganges. The director is passed first, then one or more beads are threaded on it and pushed home. The instrument may then be fixed and withdrawn. Possibly in resilient and other strictures the act of drawing the instrument back and forwards would have a good effect. The exact position of the stricture can be ascertained by passing a bead as far as the stricture and then clamping the ring at the orifice of the urethra.

Thomas JACKSON, L.R.C.S.Edin. Colwyn Bay.

\title{
A UTOMATIC WOUND
} RETRACTORS.

THE accompanying illustration represents a pair of wound retractors threaded on a rubber cord, and designed to obtain traction on the edges of a wound in operations on the neck, limbs, \&c. Each retractor consists of a flat piece of steel, one end of which is fashioned into a pair of hooks, blunt or sharp. The other ent is bent upwards, is perforated at the angle by a hole through which the rubber cord passes, and the latter is then clipped into a vertical slot after the manner of fixing the ends of a field tourniquet. The instrument may be held or altered in position by grasping the grooved side of the " handle" portion. To use the retractors (say, for excision of a varicose vein of the leg) thread one on each end of a place two pieces of flannel. At $c$ there is an airway the lumen FULL SIZE

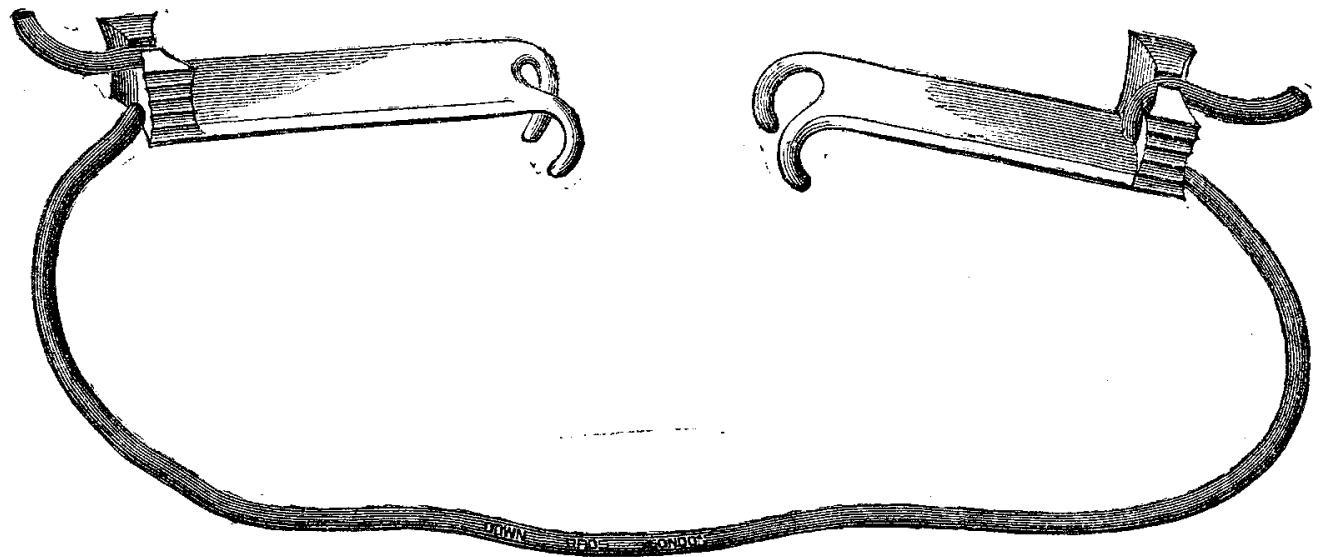
of which is quite double that of the adult trachea. At D (Fig. 2) there is an opening for the tube of a Junker which can be attached to a vulcanite plug filling the opening. This tube is supplied with the mask. Also, to the flannel at $\mathrm{E}$ a sponge can be affixed if it be desired to give ether, in which case a single piece of flannel large enough to cover the mask from $\mathrm{E}$ to $\mathrm{F}$ should be used. The advantages of the mask are :-1. It allows a free intake of air at all times during anresthetisation, so that with ordinary care coughing and swallowing, struggling, asphyzia, \&c., are noticeably absent. 2. The position and dimension of the airway, which, while permitting absolutely

long length of rubber cord or thick tubing and lay its centre beneath the limb; after the skin incision hook a retractor into the wound edges on either side, making the tension sufficient by drawing the cord through the base of either hook and fastening off. Equal or unequal gaping of the wound unimpeded respiration, is so placed that with each inspiration the vapour is inhaled in amounts varying with the quantities of anæsthetic used. 3. The ease with which the anæsthetic can be dropped on the mask without risk of touching the patient's face. 4. Its cleanliness. The covers for the upper 
and lower parts consist of tlannel (sterilised when necessary) cut to shape; these can be put on or removed in a few seconds; the frame, being all of metal, can obviously be completely sterilised-matters of considerable importance in the case of operations on the head, neck, thorax, \&o. 5. 1 chloroform administration can, if desirable, be commenced by using with this mask a drop bottle, such as Thomas's, \&c., until the patient is well into the second stage, when the remainder of the anæsthetisation can be continued with a Junker (attached to the mask in the first instance). The anæesthetist who knows the difficulty of getting a nervous or alcoholic patient comfortably under within a short period possesses in this apparatus the means of accomplishing that end with safety and satisfacticn. The patient also hears nothing of the bellows and the bubbling of the Junker. This latter consideration is by no means unimportant when one bears in mind how destrable it is to avoid adding to the natural fears of a child or neurotic patient.

WILLIAAI E. BuRTON, L.R C.S.Irel, Lic. Med. T.C.D.

\section{THE PNEUMATIC MEDICATOR AND INJECTOR.}

MEDICATED AIR has been in use in America for some years for the treatment of catarrh of the head, ears, nose, throat, and lungs with marked success, and especially for the cure of catarrbal dea'ness. It has lately been introduced into Great Britain and has been equally successful. But it appeared to me that better results would be obtained in many cases-such as bronchitis and phtbisis-if the temperature of the medicated air could be raised or lowered, made dry or moist, as the conditions of the case required,

Instrument for Producing Hot or Cold, Dry or Mroist, Medicated Air.

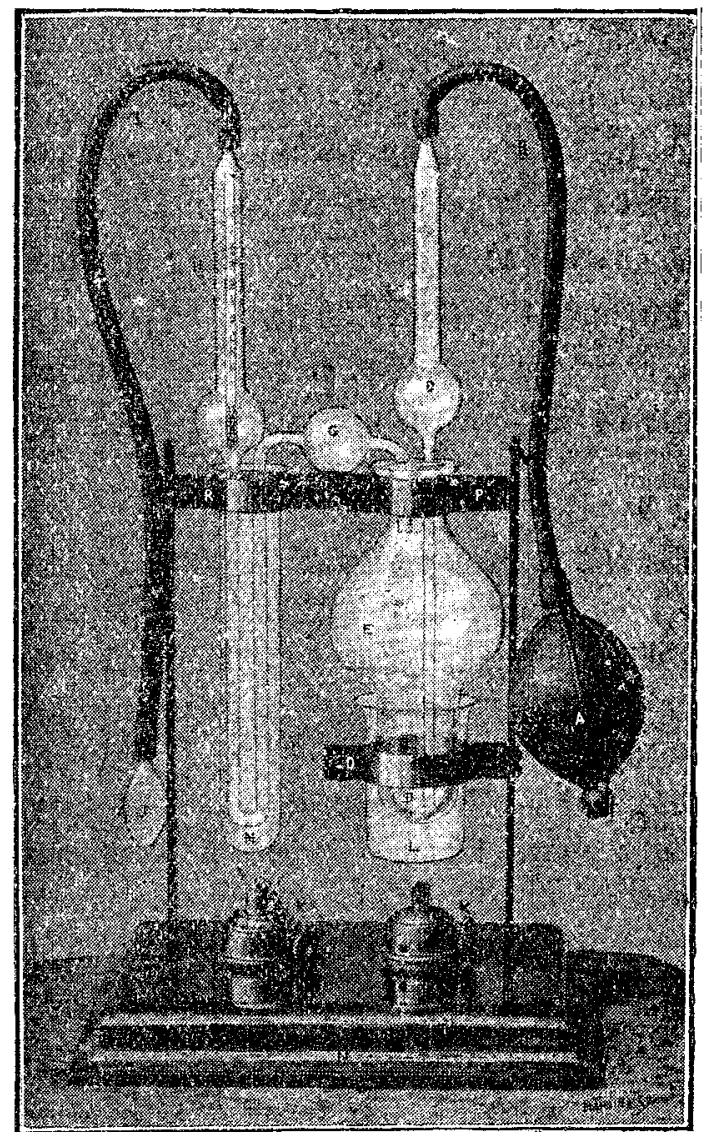

$A$, Rubber blowing bulb. $B$, Rubber tube connecting blowing bulb with straight glass tube. c, Straight glass tube. D, Reservoir for holding medicine. E, Air chamber for medicated air. $F$, Rubber cork for holding glass tubes. G, Long bent glass tube containing thermometer. $H$, Thermoneter in long bent glass tube. I, Rubber tube connecting long bent glass tube with mouth- or nose-piece. $\mathrm{J}$, Glass nose- or mouth-piece. $\mathrm{K}$, Spirit lamp for heating water batas. L, Water bath for heating medicine in reserrair or for cooling medicine by filling with ice. M, Water bath for heating medicated air in long bent glass tube which passes through it. N, Stand containing spirit lamp. for supporting air chamber and reservoir. R, Holder for
supporting long water bath.

as up to the present the medicated air has only been used in a dry state at the temperature of the room in which the patient used the instrument. To meet these requirements where better results would be obtained by raising or lowering the temperature and making the heated medicated air dry or moist, I have constructed an instrument with which the patient can either use the medicated air at the temperature of the room in which the instrument is use $d$ or the temperature can be raised or lowered, and the heated medicated air can also be made dry or moist as may be required by the nature of the case.

D. JoHNston, L.R.C.P. Edin., \&c.

\section{NINETEENTH REPORT OF THE GENERAL PRISONS BOARD, IRELAND.}

IN his work on "Penological and Preventive Principles" the secretary of the Howard Association has referred in complimentary terms to the successful methods employed in the management of the Irish prisons. That the same policy is still being pursued is apparent from a perusal of the present report, which contains evidence that the Irish Prison Commissioners are concerned in maintaining a high standard of efficiency in the administration of the establishments under their charge. It is more than probable that the satisfactory state of affairs revealed in the report is in a measure due to the fact that one of the members of the Irish Board is a representative of the medical profession. In this respect both the English and Scottish Boards labour under a distinct disadvantage, for there can be no doubt that the question of the treatment of the criminal is gradually but surely assuming a more scientific aspect. His physical and psychological peculiarities are being extensively and exhaustively studied, and the relations of insanity and crime are constantly attracting attention. The health of prisoners, mental as well as bodily, their dietary, and their sanitary surroundings are matters of weighty importance, deserving special recognition and requiring skilled supervision. The report now under consideration is the record of a year's quiet and uneventful work. The course recently adopted in England of amalgamating the statistics of the local and convict prisons has been followed here. There has been a slight increase in the number of criminal prisoners committed to local prisons. The behaviour has ben good, and it is gratifying to note a gradual diminution in the number of prison punishments during the past few years. The deathrate was remarkably low-viz., 256 per 1000 . One suicide is reported. Three cases of typhoid fever occurred, but it is mentioned that the disease was incubating when the prisoners were admitted. Sixty-two prisoners were released on medical grounds; they included the cases of twenty-three women far advanced in pregnancy. There were 103 cases of insanity, being 28 in excess of the number in the previous year. Eighty were found to be insane on reception, and the remainder whilst undergoing sentence. Particulars of the individual cases are given in Table XIV. As it stands, this table is not of much practical value. With further detailed analysis and subdivision it would undoubtedly prove useful, both from a psychical and medico-legal point of view. The average daily population of the local prisons was 2335 ; that of the convict prisons was only 429. The conduct of the long sentence prisoners seems to have been exemplary, and in no instance was corporal punishment resorted to. One convict died, ten were released on medical grounds, and six became insane and were transferred to the Central Criminal Asylum at Dundram. The number of juveniles convicted and sent to prison is annually becoming less. Special rules have been adopted for their treatment; the operation of these rules ought to prove beneficial. The whole report a ffords evidence that the duties of the Board are being discharged in a creditable manner.

Clinical Demonstrations to Practitioners.At the request of the Glasgow Town Conncil the visiting physician to the city fever hospital at Belvidere has agreed to give a series of clinical demonstrations on the cases of smallpox under treatment in the hospital. The demonstrations are free to all practitioners who conform to the conditions as to re-vaccination and such other precautions as are very properly demanded. There can be no doubt that this arrangement will be welcomed by the profession, and all the more so that-fortunately from a public point of view-opportunities for seeing small-pox are now so rare in the city. 